\title{
DEVELOPING CROSS-CULTURAL COMPETENCE
}

Interviewer: Marthe Giguère, Editor-in-Chief, Pédagogie collégiale

In the fall of 2011, 53\% of nursing students ${ }^{1}$ at the Cégep de Saint-Laurent had been born outside of Canada. Of that number, a high percentage had been living here for under five years-a testimony to a change in Quebec society that merits recognition by the province's colleges. Post-secondary academic institutions constitute an important setting for the integration of immigrant students, especially if those students are confronted with professional values that might be at odds with their personal cultural values. Similarly, when providing services to people from different cultures, it may prove imperative for college educators to have the tools required to understand them.

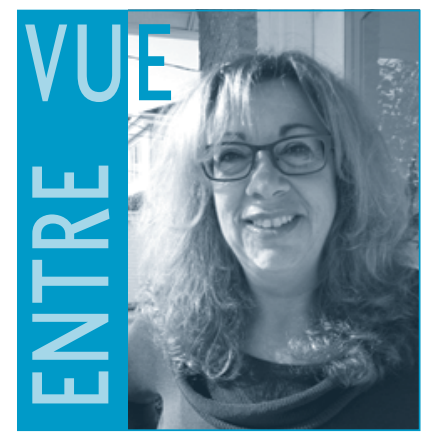

Viviane FOURNIER, a nursing teacher at the Cégep de Saint-Laurent, has developed an approach aimed at developing cross-cultural competence in health-program instruction-an essential skill for college educators if they hope to build bridges between people of different cultures. Although targeting healthcare personnel, the "Modeler, intégrer et favoriser la réussite-Formation pour soutenir le développement de la competence inter-culturelle en l'enseignement des programmes de santé" [Modelling, Integrating and Promoting Success - How to Support the Development of Cross-Cultural Competence in Healthcare-Program Instruction] online course will undoubtedly inspire teachers in other fields as well.

\section{PÉDAGOGIE COLLÉGIALE:}

Where did you get the idea to develop a program on crosscultural competence?

\section{VIVIANE FOURNIER:}

In the healthcare system, we often treat people from various different cultures; as a nurse, I was confronted with that reality. Whether we're dealing with birth, the way we care for children, or death, it's easy to understand that our cultural values strongly influence the way we see various life events. I have often felt poorly equipped to deal with these situations in a professional setting. I didn't know how to react, and as a result made some real cultural "faux pas". When I was getting into teaching, I experienced the same discomfort when faced with a diverse student population. Because I felt the need to become better equipped to cope with our society's multicultural realities, I enrolled in the cross-cultural instruction [Pédagogie interculturelle] course offered by PERFORMA. The course helped me develop my skills and aroused my interest in the issue; I quickly saw that putting this skill to work in my teaching was paramount.

I also noted that these same multicultural realities existed within work teams. For example, I witnessed a misunderstanding undermine the working relationship between a student nurse and the nurse in charge. Both were Francophones from Europe, and could have been expected to hold basically the same view of things. However, this was not at all the case, and the tension between them was poisoning the work atmosphere. Thanks to cross-cultural analysis, I was able to understand what was actually going on. The nurse came from a culture that valued personal independence, while the student was from a conservative culture. He considered the nurse his superior, and was waiting for her to provide answers to questions on patient care. The nurse in charge of the internships, on the other hand, hoped to see the student nurse demonstrate independence, an attitude that is essential to the profession. She felt the student nurse was passive and not very resourceful. The culture shock experienced by both parties limited their collaboration, with the student nurse feeling trapped by the nurse's negative perceptions of him.

This is only one illustration of the fact that, since many of our students are first-generation immigrants, we must ensure they properly grasp the values of their profession-values that occasionally run counter to their cultural values. When I had the idea for a course to develop cross-cultural competence, I also thought about nurses who had gotten their training outside of Canada and were already working in the healthcare system. These individuals, as well, might benefit from support in order to better adjust to our healthcare system.

How has cross-cultural competence been integrated into the nursing program?

vf Many of the skills in question involve interacting with different patient groups, medical-surgical nursing, and caring for children and teens, to give just a few examples. To enable students to develop these skills, the nursing program includes eight to ten internships that take place

\footnotetext{
In this article, the feminine has been used to refer to all nurses, teachers, and nursing students, as most are women.
} 
under different conditions and in different settings. These workplace changes are essential in enabling students to prepare themselves adequately for the realities of the world of healthcare. Since the cross-cultural aspect is one of the issues to which nurses must adapt, developing cross-cultural competence is vital to treating patients in different contexts.

The course is intended to develop one skill in particular: changing one's cultural perspective. This skill, which is a vital part of the nurse's professional role, means distancing oneself from one's personal values, whether in a teaching or a nursing context. Developing cross-cultural competence means that students must base their practices on a reference framework that allows them to enter others' "cultural space".

Do nurses have to be familiar with the customs of every culture they might have to deal with?

vf Not at all! That would be the case if the approach were culture-specific-i.e., if it involved recognizing that each culture has its own particular characteristics and getting acquainted with those characteristics in order to interact. However, that is not my approach. I'm from Quebec, but I realize I can't assume that my views are shared by everyone in the province; having a common ethnic origin does not automatically mean we share the identical cultural values. Instead, I opted for the model proposed by Schwartz (1999); his theory on value categories makes it possible to compare different cultures (see Figure 1).

This approach consists, not in prescribing behaviour for interacting in a specific manner with the members of a given culture, but rather in equipping ourselves to recognize the overall group of values with which a certain individual identifies. This theory proposes two types of opposing values that can be categorized in keeping with three main dimensions: the first involves how we define ourselves; the second, the behaviour we adopt in public; and the third, our view of our relationship with the world. Schwartz's model highlights the fact that our way of dealing with things is based primarily on our cultural construction of values. Some cultures, for example, tend to accept the course of events as they happen (Harmony), while, with others, those events must be acted upon in order to be mastered (Mastery). If we are aware of this fact, we will be able to understand how the other person reacts and take that reaction into account, even if we are not all that knowledgeable about the traditions linked to the cultural values in question.
According to Schwartz's model, what are the advantages of developing cross-cultural competence?

vf Explaining the professional model and its cultural foundations results in a significant change for nurses, helping them fully assume their professional responsibilities and adopt an approach that takes account of their patients' cultural differences. As regards the former, I should point out that accountability is crucial in the nursing field: whatever the cultural context, each nursing student must learn that it's vital to acknowledge her mistakes and take responsibility for them. This model will not change, and students have an obligation to adopt it. If they come from a culture that prizes Harmony, they may tend to not acknowledge that responsibility, to attribute whatever happens to fate. In our professional context, however, this is simply unacceptable. When students understand this, it's easier for them to adopt the behaviour expected of them.

Similarly, recognizing cultural differences helps us avoid certain cultural faux pas. By way of illustration, take the situation of a nurse from a culture that favours Mastery being confronted with a patient from a culture that prefers Harmony. When faced with an illness, this patient might accept it as fate; the resulting passive behaviour could be interpreted as depression, and lead to treatment that does not reflect the patient's actual mental state. If we can explain this cultural difference, it becomes easier to determine whether patients truly understand the consequences of their decisions. The goal of this approach is therefore to allow nurses to identify the behaviour expected by their profession and give the patient the means to establish true cross-cultural communication, so as to provide the appropriate care.

For whom is your course intended, and what shape does it take?

vf The course is intended for students, teachers, and healthcare personnel. The approach involves the analysis of cultural values and provides the tools and methods needed to allow course users to behave in accordance with their professional role, and to take account of the values of people from a culture other than theirs.

The individuals I thought of first in developing the course were students in the province's three healthcare-education programs: Assistance in Healthcare Facilities (vocational diploma); Health, Assistance and Nursing (vocational diploma); and Nursing (diploma of college studies).

\footnotetext{
2 Schwartz, S. H. 1999. "A Theory of Cultural Values and Some Implications for Work", Applied Psychology: An International Review 48(1):23-47.
} 
The course offers video clips illustrating best practicesthat is, how to behave appropriately and effectively in a given cross-cultural context. The clips focus on different care situations: eldercare, teamwork, helping relationships in a surgical context, administering medication in a pediatric context, and post-operative clinical evaluation. While all five clips, which are related to one or more of the program skills to be developed, are designed for Nursing students, four are also relevant for those enrolled in Healthcare, Assistance and Nursing, and three are also pertinent for those enrolled in Assistance in Healthcare Facilities.

Since the teachers show the video clips in their classes, we had to ensure they were in a position to support their students in developing cross-cultural competence. With them in mind, we developed four online self-study modules. The first discusses the issue of students who are recent immigrants. In the second, we explore the learning theories and teaching strategies appropriate for those students. The third module explains Schwartz's model and how to implement it. The fourth and final module features the video clips, putting them into context within each individual curriculum concerned. A complementary module gives teachers direct access to the video clips to be shown to their students.

These self-study materials and video clips are available free of charge, ${ }^{3}$ and the course is open to anyone interested. An online certification exam is also provided to individuals wishing to take it for credit, provided they pay a fileadministration fee and take the online evaluation. Such certification could be of interest to members of the Ordre des infirmiers et infirmières, which requires 20 hours of training annually, including seven for credit.

\section{Do students feel the video clips help them develop cross- cultural competence?}

vf Our project is still in its infancy, but participants have told us they've made important discoveries; their comments to that effect can be read on the course Website (Module 4). While we focus mainly on the nursing-program competency that deals with the social and cultural realities related to health care (01Q6), each video clip discusses several other competencies as well, which are clearly identified in the fourth module. I should add that the approach is also intended to prepare students for their internship. Viewing the clips makes them aware of the significance of cultural differences - a way of equipping them against culture shock before they face such situations in the real world, meaning they are much better equipped when they do their internship.
Because it's important to show students how to integrate this new skill into their practices, during a pediatrics internship, some teachers asked their students to refer to Schwartz's theory in identifying a cultural value adopted by their patient or the latter's family. The students had to explain to what degree, if any, this value was in line with their own values, and to what extent, if any, they had adjusted to their patient's cultural values in relation to their professional role and the care given. The feedback we got from third-term students was extremely positive.

Your project was the result of a collaborative effort between high schools and colleges. How did that come about?

vf The heart of nursing is the nursing team, which is made up of a nurse's aide, a certified nursing assistant, and a nurse. These individuals work closely with healthcare institutions. I was already in contact with a vice-principal at the École des métiers des Faubourgs-de-Montréal (which falls under the Montreal School Board) in relation to regional management for nursing internships. We learned that Éducation Montréal was looking to establish joint projects involving college-level technical instruction and high-school vocational training. Éducation Montréal is an inter-level committee whose objective is to renew the organization and deployment of vocational and technical training in order to ensure better access for the students from all horizons and of all origins, as well as to better match the public and private sectors' requirements for qualified labour. ${ }^{4}$ About 30 people contributed to this project.

Do you feel this training is transferable to fields other than healthcare?

vf Absolutely. The approach developed is transferable to any other vocational or professional field; it would simply be a matter of making video clips on best practices for those fields (IT, water purification, early childhood education, etc). Cultural competence allows us to objectively examine the cultural foundations on which our views are based. It then becomes possible to distance ourselves from those views, so as to ensure that every act is truly based on professional values. Cross-cultural competence also provides the tools we need to respect and better serve clients. For these reasons, any field based on professional values would gain from cross-cultural competence. 1

\footnotetext{
3 [www.cegep-st-laurent.qc.ca/soins/formation-em]. TR: In French only.

4 Taken from [www.educationmontreal.org]. TR: In French only.
} 


\section{SCHWARTZ'S MODEL: UNDERSTANDING CULTURAL DIFFERENCES}

Schwartz identifies three basic value dimensions, each characterized by opposing, bipolar values, in accordance with which societies mold their relationships with work and interpersonal relations. In his view, these dimensions determine modes of operation, organization, and individual behaviour.

\section{CONSERVATISM VERSUS AUTONOMY (intellectual and affective)}

The first dimension defines the relationship between the individual and the group (collectivity). With respect to individuals' views of who they are and how they identify themselves, two opposing, fundamental values-Conservatism and Autonomy (intellectual and affective) — are at play. This dimension involves how individuals perceive their ties to the group, their intrinsic identification with that group, and their common view of life within it. On one hand, Conservatism advocates conservative behaviour: maintaining the status quo, restraining any act or question that could compromise the group's cohesion and solidarity, and respect for the social order. On the other, we have the value of Autonomy, which, according to this model, is divided into two sub-values: intellectual autonomy and affective autonomy. The perception at the core of this value is that each individual is unique, and able to ascribe meaning to life on his/her own. Individuals are encouraged to rapidly develop intellectual autonomy, which is characterized by curiosity, the pursuit of one's own ideals, and the establishment of one's own definitions. Affective autonomy is displayed by the search for positive experiences - experiences that are pleasurable, exciting, and satisfying. Schwartz says that this pole, both intellectual and affective, is the most powerful in our society.

\section{HIERARCHY VERSUS EGALITARIANISM}

The second dimension, which deals with responsible behaviour that allows society to function, opposes the values of Hierarchy and Egalitarianism. Hierarchical relationships constitute a type of insurance that each of us will adopt responsible behaviour that maintains the social order. This value assumes that power will be distributed unevenly, and be held by a few individuals in positions of authority with financial resources generally inaccessible to most of the population. Egalitarianism, on the other hand, favours collective well-being and the sharing of resources and comprises the principles of honesty, social justice, and equity. Although Schwartz qualified French-Canadian society as being more egalitarian than hierarchical, we must take into account that organizational cultures depend on their management and management philosophy, with the result that, within any organization, the value pole may differ from that of the society in which that organization operates.

\section{MASTERY VERSUS HARMONY}

The third dimension involves the relationship between humankind, the universe, and society. In cultures that emphasize Mastery, individuals value self-assertion: they establish their own objectives, display ambition, dare to make their own personal choices, and actively develop their skills. At the other end of the spectrum, cultures that esteem Harmony demonstrate a deep respect for nature, other human beings, and beauty. The value of Harmony requires the acceptance of the world as it is, and the desire to fit into that world, rather than the wish to model or exploit it. Schwartz (1999) puts Quebec society about midway between these two poles, a bit closer to Mastery than Harmony.
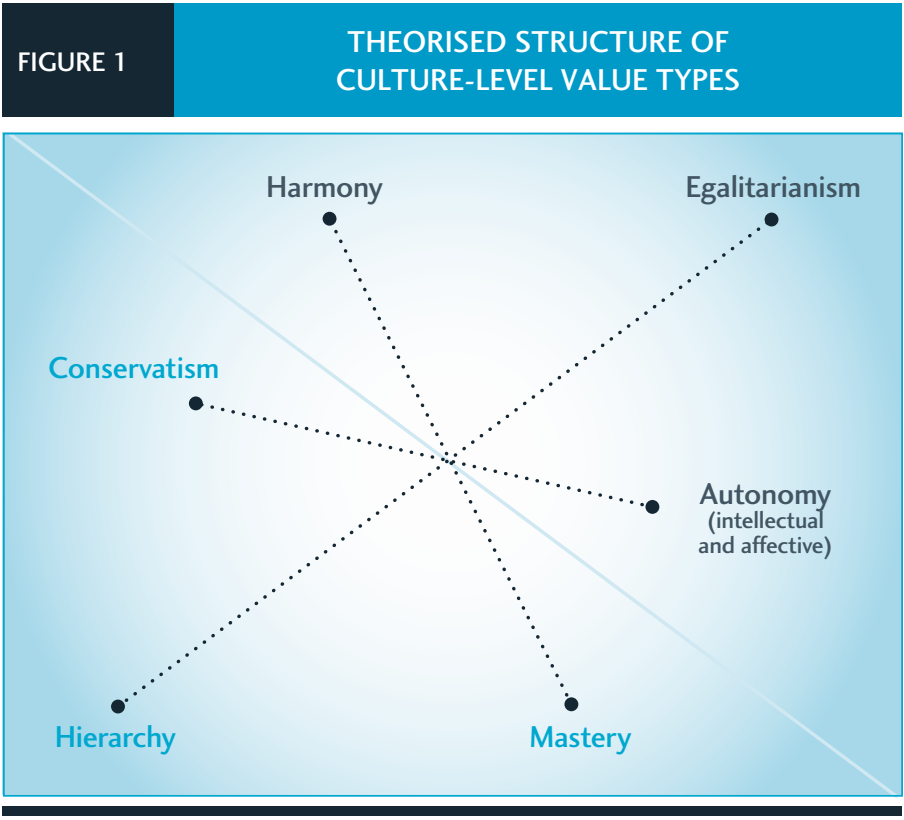

Both the English- and French-language versions of this article have been published on the AQPC website with the financial support of the Quebec-Canada Entente for Minority Language Education. 